\title{
Nietzsche e a prerrogativa da ciência como forma de inverdade: visão de mundo científica versus visão de mundo cristã ${ }^{*}$
}

\author{
Eder Corbanezi**
}

Resumo: Partindo da análise de $O$ Anticristo, investigamos a função que Nietzsche atribui à ciência, entendida como forma de inverdade, em relação a outras formas de inverdade, como o cristianismo. Primeiro, buscamos mostrar que, nesse escrito, o autor estabelece a incompatibilidade entre ciência e cristianismo atribuindo-lhes características específicas e inconciliáveis (como a probidade intelectual, própria da ciência, e a exigência de fé, típica do cristianismo). Depois, evidenciamos que qualificativos como "falsa", "errônea", "fictícia" e "mentirosa", aplicados em tom pejorativo à concepção religiosa de mundo em $O$ Anticristo, determinam igualmente, em outros escritos, o conhecimento científico. Ora, se as concepções de mundo cristã e científica têm características semelhantes, por que Nietzsche recorre à ciência para rejeitar o cristianismo?

Palavras-chave: Ciência, cristianismo, verdade, inverdade, erros-verdades, erros-erros.

\footnotetext{
* A primeira versão deste trabalho foi publicada com o título "Le recours à la science chez Nietzsche: une étude à partir de L'Antéchrist", em DENAT, C.; WOTLING, P. (Orgs). Nietzsche. Les textes de 1888. Reims: Éditions et presses universitaires de Reims, 2020. Para a presente publicação, realizamos modificações no texto e no título. $\mathrm{O}$ artigo resulta de pesquisa apoiada pela Fapesp (processo 2016/04380-0, Fundação de Amparo à Pesquisa do Estado de São Paulo).

** Universidade Federal de São Paulo (Unifesp), São Paulo, São Paulo, Brasil.

ORCID https://orcid.org/0000-0001-7916-5788

Correio eletrônico: edercorbanezi@hotmail.com
} 
Corbanezi, E.

Tomando como ponto de partida a análise de $O$ Anticristo, propomo-nos a investigar certo aspecto do papel que Nietzsche atribui ao pensamento científico. De início, buscamos mostrar que, nesse escrito, o autor procura estabelecer uma relação de incompatibilidade entre ciência e cristianismo em função das maneiras opostas pelas quais eles consideram a noção de verdade, observada sob três ângulos conectados, a saber, do ponto de vista dos valores, do conhecimento e dos modos de realidade. Em seguida, esperamos fazer notar que Nietzsche pretende basear aquela incompatibilidade na distribuição de características específicas e inconciliáveis, tais como a probidade intelectual, própria da ciência, e a exigência de fé, típica do cristianismo. No entanto, depois de expor essa distribuição de características específicas e incompatíveis, evidenciamos que qualificativos como "fictícia", "errônea", "falsa" e "mentirosa", aplicados em tom pejorativo à concepção religiosa de mundo em $O$ Anticristo, determinam igualmente, em outros escritos de Nietzsche, a concepção científica de mundo. Por fim, examinamos o problema que daí decorre: se as concepções de mundo tanto cristã como científica apresentam as mesmas características, por que Nietzsche recorre à ciência para rejeitar o cristianismo? É a análise desse problema que nos permitirá identificar uma determinada função atribuída à ciência pelo autor de Zaratustra.

O Anticristo apresenta uma crítica ao cristianismo entendido como obstáculo a uma forma superior de vida e de humanidade. Segundo Nietzsche, "o cristianismo tomou o partido de tudo o que é fraco, baixo, malogrado" (AC/AC 5, KSA 6.171). Além disso, ao considerar a compaixão não apenas como uma virtude, mas como " $a$ virtude", essa religião "cruza a lei do desenvolvimento, que é a lei da seleção" (AC/AC 7, KSA 6.173)². A compaixão, com efeito,

1 Tradução de Paulo César de Souza, doravante designado PCS.

2 Tradução de Rubens Rodrigues Torres Filho, doravante designado RRTF.

62 | Cad. Nietzsche, Guarulhos/Porto Seguro, v.42, n.1, p. 61-88, janeiro/abril, 2021. 
Nietzsche e a prerrogativa da ciência como forma de inverdade...

"conserva o que está maduro para sucumbir, arma-se em favor dos deserdados e condenados da vida e, pela multidão de malogrados de toda espécie que mantém firmes na vida, dá à vida mesma um aspecto sombrio e problemático" (AC/AC 7, KSA 6.173, RRTF). Desse modo, "a religião da compaixão" (AC/AC 7, KSA 6.172, RRTF) contribui para o cultivo do que Nietzsche denomina "o animal doméstico, o animal de rebanho, o animal doente homem - o cristão..." (AC/ AC 3, KSA 6.170, PCS). Mas o cristianismo vai além. Trava "uma guerra de morte" contra um "tipo mais elevado de homem" (AC/AC 5, KSA 6.171, PCS), precisamente aquele que, na visão de Nietzsche, "deve-se cultivar, deve-se querer, como de mais alto valor, mais digno de vida, mais certo de futuro" (AC/AC 3, KSA 6.170, PCS). Desse homem superior, que representa "os instintos de conservação da vida forte", o cristianismo faz "o homem mau" (AC/AC 5, KSA 6.171, PCS).

Com base em sua própria concepção de vida, entendida como “instinto de crescimento, de duração, de acumulação de forças, de potência" (AC/AC 6, KSA 6.172, RRTF), Nietzsche estima "bom [...] tudo o que eleva o sentimento de potência, a vontade de potência, a própria potência no homem" (AC/AC 2, KSA 6.170, PCS, trad. modificada). Inversamente, ele julga "ruim [...] tudo o que vem da fraqueza" (AC/AC 2, KSA 6.170, PCS, trad. modificada). Ora, se o cristianismo significa "a ativa compaixão por todos os malogrados e fracos", que, segundo o autor, "devem perecer" (AC/AC 2, KSA 6.170 PCS), então essa religião é naturalmente alvo de sua crítica ${ }^{3}$. Em seu ataque contra a visão cristã do mundo, Nietzsche defende a ideia de que ela inverte a aplicação dos conceitos de

3 Num fragmento póstumo de 1888, Nietzsche censura o cristianismo na medida em que, "em vez de encorajar à morte e ao autoaniquilamento, protege tudo o que é malogrado e doente e faz com que se reproduza". O autor de Assim falava Zaratustra, ao contrário, pergunta-se "com que meios se alcançaria uma forma estrita do grande niilismo contagioso: uma forma que, com consciência científica, ensinasse e praticasse a morte voluntária..." (Nachlass/FP 1888, 14 [9], KSA 13.222). A respeito do eugenismo na filosofia de Nietzsche, cf. Salanskis, 2013. 
Corbanezi, E.

verdadeiro e de falso considerados como juízos de valor. É que o cristianismo considera como verdadeiro tudo o que danifica a vida e como falso, tudo o que a favorece:

O que um teólogo percebe como verdadeiro tem de ser falso: aí se tem quase que um critério da verdade. [...] Até onde vai a influência do teólogo, o julgamento de valor está de cabeça para baixo, os conceitos de "verdadeiro" e "falso" estão necessariamente invertidos: o que é mais prejudicial à vida chama-se "verdadeiro", o que a realça, eleva, afirma, justifica e faz triunfar chama-se "falso"... (AC/AC 9, KSA 6.175-176, PCS)4.

Além de posicionar-se com base em sua própria concepção de vida ascendente e de vida decadente, Nietzsche supõe, portanto, que a ideia de verdade, quando utilizada em julgamentos de valor que qualifiquem o que é digno da mais elevada estima, não convém ao que implique, sob qualquer forma, a negação da vida e do mundo. Daí asseverar o autor de $O$ Anticristo que os sacerdotes invertem os julgamentos de valor. Eis a consequência e o pressuposto de tal inversão:

Enquanto o padre vale ainda como uma espécie superior de homem, esse negador, caluniador, envenenador da vida por profissão, não há nenhuma resposta para a pergunta: o que é verdade? Já se tem a verdade de pontacabeça, quando o advogado consciente do nada e da negação vale como representante da "verdade" (AC/AC 8, KSA 6.175 RRTF).

De fato, assegura Nietzsche, o "sacerdote dominou até agora" e "determinou os conceitos de "verdadeiro' e "não verdadeiro'”" (AC/ AC 12, KSA 6.179, PCS). Ao fazê-lo, todavia, negligenciou a ciência:

4 Mais adiante, insiste Nietzsche: “Toda palavra na boca de um 'primeiro cristão' é uma mentira, toda ação que ele realiza, uma falsidade de instinto - todos os seus valores, todos os seus fins são nocivos, mas quem ele odeia, o que ele odeia, isso tem valor... O cristão, em especial o cristão sacerdote, é um critério de valores" (AC/AC 46, KSA 6.224-225, PCS).

64 | Cad. Nietzsche, Guarulhos/Porto Seguro, v.42, n.1, p. 61-88, janeiro/abril, 2021. 
Nietzsche e a prerrogativa da ciência como forma de inverdade...

"Que importa a ciência para um sacerdote? Ele está muito acima disso!" (AC/AC 12, KSA 6.179, PCS) 5 .

Ao opor-se aos julgamentos de valor invertidos pelo sacerdote, que considera como verdadeiro o que prejudica a vida e como falso o que a favorece, Nietzsche apoia essa sua posição em outra recusa. $\mathrm{O}$ filósofo rejeita os procedimentos que outrora se estimavam adequados para determinar o que se deve qualificar de verdadeiro ou de falso:

Não subestimemos isto: nós mesmos, nós, espíritos livres, já somos uma "transvaloração de todos os valores", uma encarnada declaração de guerra e de vitória em relação a todos os velhos conceitos de "verdadeiro" e "não verdadeiro" (AC/AC 13, KSA 6.179, PCS, trad. modificada).

Um exemplo desses antigos procedimentos é oferecido pelos filósofos que, "em quase todos os povos", são "apenas o prosseguimento do tipo sacerdotal” (AC/AC 12, KSA 6.178, PCS). Desprovidos de "consciência intelectual", eles ignoram "as exigências primeiras da retidão intelectual” (AC/AC 12, KSA 6.178, PCS) e valorizam condutas que, a rigor, não servem para estabelecer o que se acredita dever qualificar de verdadeiro e real. É assim que "tomam os 'belos sentimentos' por argumentos, o 'peito erguido' por um fole da divindade, a convicção por critério da verdade" (AC/AC 12, KSA 6.178, PCS $)^{6}$. A esse modo filosófico-sacerdotal de estabelecer e de sustentar pretensas verdades opõe Nietzsche os métodos científicos de sua época, cujos requisitos foram alvo de desprezo por muito tempo:

\footnotetext{
5 A oposição entre ciência e religião já havia sido mencionada: "Exatamente como o sacerdote, o idealista tem na mão todos os grandes conceitos (- e não só na mão!), com benévolo desprezo ele os põe em jogo contra o 'entendimento', os 'sentidos', as 'honras', o 'bem viver', a 'ciência', ele vê tais coisas abaixo de si, como forças nocivas e sedutoras, sobre as quais 'o espírito' paira em pura "para-si-mesmidade"' (AC/AC 8, KSA 6.174-175, PCS).

6 Cf. também AC/AC 52, KSA 6.232-234. Para uma análise da "psicologia da crença" do cristianismo, cf. Sommer, 2000, pp. 475 e seguintes.
}

Cad. Nietzsche, Guarulhos/Porto Seguro, v.42, n.1, p. 61-88, janeiro/abril, 2021. | 65 
Corbanezi, E.

As percepções mais valiosas são alcançadas por último; mas as percepções mais valiosas são os métodos. Todos os métodos, todos os pressupostos da cientificidade de hoje tiveram contra si, por milhares de anos, o mais profundo desprezo; por causa deles o indivíduo era afastado do convívio com pessoas "honestas" - era considerado "inimigo de Deus", desprezador da humanidade, "possesso". Como natureza científica era chandala... Tivemos contra nós todo o páthos da humanidade - sua noção daquilo que deve ser verdade, do que deve ser o serviço da verdade (AC/AC 13, KSA 6.179, PCS).

Além de inverter o uso das noções de verdadeiro e de falso nos julgamentos de valor, o sacerdote desconsidera, segundo Nietzsche, as exigências que, de um ponto de vista cognitivo, a ciência admite como válidas para estabelecer o que se pode e se deve designar como verdadeiro no sentido de correto e de real. Assim, o raciocínio do autor de $O$ Anticristo supõe que os julgamentos de valor devem ser submetidos à apreciação cognitiva científica. Desse modo, ele dá a entender que, à diferença do cristianismo, a ciência seria capaz de julgar corretamente, subsumindo à noção de verdadeiro o que realmente favorece a vida e à noção de falso o que efetivamente a prejudica. Portanto, no âmbito cognitivo, a ciência desempenha o papel de autoridade e estabelece os requisitos para o emprego correto dos qualificativos "verdadeiro" e "falso". Mais do que isso, o que se considera como verdadeiro sob o ângulo cognitivo e científico deve ser decisivo em relação ao que se deve considerar como verdadeiro nos julgamentos de valor em que se subsume à noção de verdadeiro o que beneficia a vida e à noção de falso o que a arruína.

O objetivo de Nietzsche, percebe-se, não é apenas inverter a inversão cristã dos julgamentos de valor em que operam as noções de verdadeiro e de falso, como se o assunto se reduzisse a mera convenção, suscetível das mais arbitrárias manipulações. Sinalizando o contrário, ele faz intervir o conceito de realidade em apoio a sua tese. 
Nietzsche e a prerrogativa da ciência como forma de inverdade...

De início, tal conceito aparece em sentido negativo. A "defeituosa ótica” do teólogo, segundo Nietzsche, "pró́be que a realidade [Realität] receba honras ou mesmo assuma a palavra em algum ponto" (AC/AC 9, KSA 6.175-176, PCS) ${ }^{7}$. Por essa razão, lê-se com frequência em $O$ Anticristo a objeção de que "nem a moral nem a religião, no cristianismo, têm algum ponto de contato com a efetividade [Wirklichkeit]" (AC/AC 15, KSA 6.181, RRTF); ao contrário, elas não são mais do que um "puro mundo de fiç̧̃oes" que "falsifica, desvaloriza, nega a efetividade" (AC/AC 15, KSA 6.181, RRTF). Mas Nietzsche não se contenta em afirmar que a representação cristã do mundo não reflete a realidade sob nenhum aspecto; ele assegura também que, para fazer ruir esse mundo imaginário, basta confrontá-lo com um ponto qualquer da realidade:

No mundo cristão das ideias nada houve que apenas tocasse a realidade: e no ódio instintivo a toda realidade reconhecemos o único elemento impulsor na raiz do cristão. Que se segue daí? [...] Um conceito fora, uma única realidade em seu lugar - e todo o cristianismo desaba!" (AC/AC 39, KSA 6.21, PCS).

Ao reiterar essa posição, Nietzsche acrescenta que, da irrealidade do mundo concebido pelo cristianismo, decorre a necessária hostilidade dessa religião em relação à ciência: “Uma religião como o cristianismo, que não tem nenhum ponto de contato

7 Sobre a irrealidade do mundo representado pelo cristianismo, cf. também, no mesmo livro, os parágrafos $15,29,39,42,47,58$ e 62 .

8 Nesse parágrafo, Nietzsche apresenta o universo fictício do cristianismo nos seguintes termos: "Somente causas imaginárias ('Deus', 'alma', 'eu', 'espírito', 'a vontade livre' - ou ainda a 'não-livre'); somente efeitos imaginários ('pecado', 'redenção', 'clemência', 'castigo', 'remissão dos pecados'). Uma transação entre seres imaginários ('Deus', 'espíritos', 'almas'); uma ciência imaginária da natureza (antropocêntrica; total ausência do conceito de causas naturais); uma psicologia imaginária (somente mal-entendidos sobre si, interpretações de sentimentos gerais agradáveis ou desagradáveis, por exemplo, os estados do nervus sympathicus, com auxílio da linguagem simbólica da idiossincrasia moral-religiosa - 'arrependimento', 'remorso de consciência', 'tentação do diabo', 'a proximidade de Deus'); uma teleologia imaginária ('o reino de Deus', 'o Juízo Final', 'a vida eterna”" (AC/AC 15, KSA 6.181, RRTF).

Cad. Nietzsche, Guarulhos/Porto Seguro, v.42, n.1, p. 61-88, janeiro/abril, 2021. | 67 
Corbanezi, E.

com a efetividade, que desmorona tão logo a realidade, em um ponto sequer, adquire seus direitos, tem, como é justo, de ser inimiga mortal da "sabedoria', que dizer, "da ciência" (AC/AC 47, KSA 6.225, RRTF).

Ora, ao afirmar que o cristianismo, na medida em que não toca a realidade e na medida em que desmorona assim que o mundo real adquire seus direitos, tem de ser inimigo da ciência, o raciocínio de Nietzsche necessariamente supõe que a ciência concerne à realidade e, por conseguinte, tem condições de arruinar a religião mencionada ${ }^{9}$.

Assim, parece-nos, a estratégia de Nietzsche consiste em estabelecer em $O$ Anticristo uma relação de incompatibilidade entre ciência e cristianismo. Para tanto, o autor evidencia os respectivos modos pelos quais eles concebem a noção de verdade considerada sob três aspectos interconectados: primeiramente, do ponto de vista axiológico, toma-se verdade como noção que opera em julgamentos de valor em que se supõe qualificar de verdadeiro o que favorece a vida e de falso o que a prejudica (o cristianismo engana-se, mas a ciência pode fazê-lo corretamente); em segundo lugar, sob o ângulo cognitivo, entende-se verdade como designação aplicável a resultados obtidos por determinados procedimentos (apropriados, no caso da ciência, e inapropriados, no caso do cristianismo); em terceiro lugar, no que diz respeito ao modo de existência, compreende-se verdade como sinônimo do que se concebe como realidade em contraste com a ficção (a ciência se vincularia com o mundo real, enquanto a concepção cristã do mundo seria pura imaginação). Para frisar a incompatibilidade entre ciência e cristianismo, Nietzsche exclama de um lado: "acabam-se os sacerdotes e deuses, se o homem se torna

9 Em Humano, Demasiado Humano, Nietzsche já se havia proposto a evidenciar os "erros" que encerram certas concepções cristãs, resultantes de uma "interpretação falsa, não científica" (MA I/ HHI 134, KSA 2.128, PCS). Após insistir na ideia de que o cristianismo repousa numa "determinada psicologia falsa" e numa "espécie de fantasia na interpretação", o autor afirma que, "percebendo a aberração do raciocínio e da imaginação, deixa-se de ser cristão" (MA I/HHI 135, KSA 2.129, PCS).

68 | Cad. Nietzsche, Guarulhos/Porto Seguro, v.42, n.1, p. 61-88, janeiro/abril, 2021. 
Nietzsche e a prerrogativa da ciência como forma de inverdade...

científico!" (AC/AC 48, KSA 6.227, PCS); e, de outro lado, assevera que "a 'crença' como imperativo é o veto contra a ciência" (AC/AC 47, KSA 6.225, RRTF). Em suma, a ciência não pode existir onde existe o cristianismo, e vice-versa, uma vez que suas respectivas condições de existência são inconciliáveis.

A exclusão mútua entre cristianismo e ciência baseia-se, portanto, numa certa distribuição de características apresentadas como específicas e incompatíveis. Ao cristianismo Nietzsche atribui de maneira pejorativa propriedades, como a exigência de fé ${ }^{10}$, que não poderiam pertencer à ciência ${ }^{11}$; à ciência, por seu turno, ele confere com conotação positiva qualidades que não conviriam ao cristianismo, como a integridade intelectual ${ }^{12}$ :

O homem de convicção tem nela [na crença] sua espinha dorsal. [...] Mas com isso ela [essa espécie de homem] é o oposto, o antagonista do verídico - da verdade... O crente não está livre para ter em geral uma consciência para a questão "verdadeiro" e "não-verdadeiro": ser honesto nesse ponto seria desde logo sua ruína (AC/AC 54, KSA 6.237, RRTF) ${ }^{13}$.

Todavia, quando se levam em conta outros escritos de Nietzsche, percebe-se que certas características atribuídas pejorativamente em $O$ Anticristo ao cristianismo, mas não à ciência, têm em realidade uma extensão bem mais geral - ou, em todo caso, geral o bastante para se aplicarem igualmente à ciência. Nesses casos não se trata, portanto, de propriedades específicas

10 Cf. AC/AC 50, KSA 6.229-230.

11 Cf. AC/AC 47, KSA 6.225-226.

12 Cf. AC/AC 59, KSA 6.247-249.

13 Para opor o cristianismo, baseado na fé, à ciência, apoiada na probidade cognitiva, Nietzsche afirma ainda: "Como a doença é da essência do cristianismo, também o típico estado cristão, a 'fé', tem de ser uma forma de doença, todos os caminhos retos, honestos, científicos para o conhecimento têm de ser rejeitados como caminhos proibidos pela Igreja. [...] 'Fé' significa não querer saber o que é verdadeiro. O pietista, o sacerdote de ambos os sexos, é falso porque é doente: seu instinto exige que em nenhum ponto a verdade obtenha seu direito" (AC/AC 52, KSA 6.232-233, PCS). Sobre a relação entre corrupção dos instintos e má filologia no cristianismo, cf. Marton, 2014a, pp. 227-244. 
Corbanezi, E.

do cristianismo, mas sim de propriedades comuns a essa religião e à ciência. Ora, se a oposição entre o cristianismo e a ciência depende de uma certa distribuição de características pretensamente específicas, então, ao se observar que em certos casos se trata a rigor de propriedades comuns, torna-se manifesta, parece-nos, uma dificuldade digna de ser investigada.

Como já mencionado, ao opor a ciência ao cristianismo, Nietzsche censura essa religião na medida em que ela constrói uma representação do mundo fictícia, errônea e mentirosa, a qual, além de não tocar a realidade, falsifica-a, desvaloriza-a e a nega. Não faria a ciência, entretanto, o mesmo? Num célebre parágrafo do Livro V de $A$ Gaia Ciência, lê-se que a ciência que faz jus ao nome não tem o direito de reivindicar mais do que ficções reguladoras:

Na ciência as convicções não têm nenhum direito de cidadania, assim se diz com bom fundamento: somente quando elas se resolvem a rebaixar-se à modéstia de uma hipótese, de um ponto de vista provisório de ensaio, de uma ficção regulativa, pode ser-lhes concedida a entrada e até mesmo um certo valor dentro do reino do conhecimento [...] (FW/GC 344, KSA 3.574, RRTF).

As ficções não constituem, pois, um momento provisório a ser ultrapassado pela ciência; elas são um limite intransponível. Aliás, é a própria ciência, afirma Nietzsche em outra página dessa mesma obra, que nos proporciona "a compreensão da universal inverdade e mendacidade [...] - a compreensão da ilusão e do erro como uma condição da existência que conhece e que sente" (FW/ GC 107, KSA 3.464, RRTF). É a ciência que nos faz conhecer o caráter universal e incontornável do não verdadeiro, da mentira, da ilusão, do erro e da falsificação. Mesmo "a melhor ciência", assegura o autor de Para além de Bem e Mal, encontra-se imersa na inverdade: ela "procura nos prender do melhor modo a esse mundo simplificado, completamente artificial, fabricado, falsificado,

70 | Cad. Nietzsche, Guarulhos/Porto Seguro, v.42, n.1, p. 61-88, janeiro/abril, 2021. 
Nietzsche e a prerrogativa da ciência como forma de inverdade...

e [...], involuntariamente ou não, ela ama o erro [...]" (JGB/BM 24, KSA 5.41-42, PCS) $)^{14}$.

Num fragmento póstumo de 1888 intitulado "A ciência", Nietzsche questiona um tipo de filosofia que considera "a lógica e as categorias da razão" não como simples "falsificação útil" para conservar uma determinada espécie de animal, mas como "o critério da verdade ou da realidade". "A ingenuidade", aponta o autor, "consistiu em tomar a idiossincrasia antropocêntrica como medida das coisas, como pedra de toque sobre 'real' e 'irreal': em suma, [em] absolutizar uma condicionalidade" (Nachlass/FP 1888, 14[153], KSA 13.336). Com essa última afirmação, todavia, ele não se limita a dizer que o critério particular em questão (a lógica e as categorias da razão) é inadequado à função a ele atribuída (a de ser o critério da verdade ou da realidade); mais do que isso, o autor dá a entender que nenhum critério poderia desempenhar semelhante papel. $\mathrm{O}$ caminho para a verdade e a realidade absolutas, portanto, encontrase interditado não só para o critério lógico, mas também para todo e qualquer critério.

Se a verdade ou a realidade em si são em definitivo inacessíveis, e se a ficção, a ilusão, o erro, a falsificação e a mentira reinam de modo fundamental, universal e necessário, então a ciência, assim como o cristianismo, inevitavelmente constrói um mundo fictício, ilusório, errôneo, falso e mentiroso.

Assim, é preciso compreender de que modo Nietzsche, para opor-se ao cristianismo, pode recorrer à ciência e pode distingui-los

14 A ciência, que nos revela a necessidade e a universalidade do não verdadeiro, está ela própria, por conseguinte, envolta em inverdades. Sob esse aspecto geral, ciência e religião assemelham-se. De fato, ao refletir retrospectivamente sobre $O$ Nascimento da Tragédia, Nietsche assevera: "A metafísica, a moral, a religião, a ciência - elas são consideradas nesse livro apenas como diferentes formas da mentira [...]" (Nachlass/FP 1887-1888, 11[415], EC). Ciência e religião se parecem ainda na medida em que se apoiam em crença, mesmo que sob formas diversas. Com efeito, se o cristianismo faz da fé um imperativo, a ciência (FW/GC 344, KSA 3.575), assim como tudo o que se toma por conhecimento (Nachlass/FP 1886-1887, 7[4], KSA 12.259-270) e por verdade (Nachlass/FP 1887, 9[38], KSA 12.352), repousa igualmente em crenças. 
Corbanezi, E.

com base no argumento de que aquela religião, negligenciando o pensamento científico, constrói um mundo fictício, ilusório, errôneo, falso e mentiroso (em suma: nem verdadeiro, nem real), como se a ciência pudesse evitar uma concepção de mundo suscetível de receber os mesmos epítetos.

Em nosso entender, a posição de Nietzsche é possível. Com efeito, defender a ideia de que em certo sentido todas as concepções de mundo consistem em ficção, ilusão, erro, falsidade, mentira, engano e aparência não significa afirmar que todas essas formas de inverdade se equivalem necessariamente. É que, embora tenham em comum o fato de serem formas de inverdade, estas não são totalmente idênticas; assim, quando consideradas em suas diferenças, elas se deixam distinguir e hierarquizar. Ora, compete precisamente à ciência a tarefa de discernir as diferenças de grau de falsidade presentes nas diversas formas de inverdade. É o que se lê num fragmento póstumo em que Nietzsche considera a falsidade e o erro não como possíveis resultados indesejados da busca por conhecimento, mas como pressupostos (tais como as noções de identidade e de permanência) do que se chama de conhecer:

Assim, certamente todo conhecimento é falso, mas ainda assim existe um representar, e entre as representações, muitos graus do falso. Estabelecer os graus do falso e a necessidade do erro fundamental como a condição de vida do ser que representa - tarefa da ciência. A questão não é saber como o erro é possível, mas: como é possivel uma espécie de verdade, apesar da inverdade fundamental no conhecimento? (Nachlass/FP 1881, 11[326], KSA 9.568) ${ }^{15}$.

O que se chama de conhecimento, sustenta Nietzsche, implica falsidade ou inverdade, o mesmo é dizer, a não correspondência da

15 Sobre a concepção nietzschiana de verdade e de conhecimento, cf. o capítulo "Perspectivismo e experimentalismo", em Marton, 2000, pp. 197-227. Sobre a ideia de que a crítica das noções de verdade e de conhecimento constitui, para Nietzsche, uma condição da filosofia, cf. Wotling, 2016, pp. 7-17 e pp. 19-89.

72 | Cad. Nietzsche, Guarulhos/Porto Seguro, v.42, n.1, p. 61-88, janeiro/abril, 2021. 
Nietzsche e a prerrogativa da ciência como forma de inverdade...

representação com o real. Assumir tal posição, porém, não significa interditar nem recusar toda e qualquer concepção de conhecimento e de verdade. Essas noções, com efeito, não se reduzem necessariamente à ideia de conhecimento e de verdade absolutos, isto é, concebidos como adequação a uma pretensa realidade em si. Aos conceitos de conhecimento e de verdade tampouco repugnam inevitavelmente a ficção, a ilusão, o erro, a falsidade, a mentira e a aparência. Pelo contrário, liberados da exigência de adequação à realidade em si e redefinidos, os conceitos de conhecimento e de verdade podem ser vistos como espécies de não correspondência. Ademais, aceitandose que as formas de inverdade não se equivalem, a distinção e a hierarquização delas não dependem forçosamente da admissão da possibilidade de um conhecimento e de uma verdade absolutos, entendidos como representações do mundo em si, para desempenhar o papel de critério. Tal distinção e tal hierarquização podem efetuarse a partir de uma ideia de conhecimento e de verdade como formas de não correspondência e, nesse sentido, de inverdade. Desse modo, Nietzsche pode adotar uma concepção de conhecimento e de verdade que não se opõe sob todos os aspectos às noções de ficção, de ilusão, de erro, de falsidade, de mentira e de aparência, e que ao mesmo tempo lhe permite distinguir e hierarquizar todas essas formas de inverdade. Assim, em vez de serem abandonados, os conceitos de conhecimento e de verdade recebem novo significado e novo papel: entendidos como formas de não correspondência, na medida em que não tocam o mundo em si, eles desempenham, entretanto, a função de critério para distinguir e hierarquizar as formas de inverdade.

Se inexiste acesso à verdade absoluta e à realidade em si, e se a inverdade se revela fundamental no âmbito do conhecimento, como pode Nietzsche, tal como ele o faz em $O$ Anticristo, conservar a distinção entre verdade e falsidade, pretendendo apoiar-se na realidade, ou melhor, na realidade tal como concebida pela ciência? 
Corbanezi, E.

Primeiro, tentemos mostrar como é possível conservar a distinção entre verdade e falsidade, após admitir a "inverdade fundamental no conhecimento" (Nachlass/FP 1881, 11[326], KSA 9.568). Ao rejeitar a possibilidade de correspondência entre pensamento e realidade em si, a face crítica da filosofia de Nietzsche anula a concepção de conhecimento e de verdade como adequação a um pretenso mundo considerado em si mesmo: "Sem a admissão de uma espécie de ser oposta à verdadeira realidade, não teríamos nada com que se poderia medir e comparar e reproduzir: o erro é o pressuposto do conhecimento. Permanência parcial, corpos relativos, processos iguais, processos semelhantes - com isso, falsificamos o verdadeiro estado de coisas, mas seria impossível dele saber algo sem tê-lo antes falsificado desse modo" (Nachlass/FP 1881, 11[326], KSA 9.567-568).

Num primeiro nível, básico e incontornável, reina a "inverdade fundamental no conhecimento" (Nachlass/FP 1881, 11[326], KSA 9.568). Visto que o conhecimento se funda em inverdades, isto é, em algo que não corresponde à "verdadeira realidade", pode-se afirmar que não é possível compreender o qualificativo "verdadeiro" como designação da correspondência entre aquilo a que ele se aplica e a realidade em si. Portanto, a oposição entre verdadeiro e falso não pode basear-se no critério da adequação entre aquilo a que se aplicam tais qualificativos e a realidade em si.

Num segundo nível, entretanto, Nietzsche faz operar de duas maneiras a oposição entre verdadeiro e falso: primeiro, ele critica o uso tradicional de tal oposição; depois, ele institui um uso próprio dessa distinção - sem desconsiderar aquele primeiro nível de inverdade fundamental, isto é, de não correspondência, e a ideia de que as inverdades não se equivalem. Em outros termos: embora seja incorreto utilizar a oposição entre verdadeiro e falso tomando por critério a adequação entre aquilo a que se aplicam tais qualificativos e o mundo em si, é possível conceber de outra maneira a distinção entre

74 | Cad. Nietzsche, Guarulhos/Porto Seguro, v.42, n.1, p. 61-88, janeiro/abril, 2021. 
Nietzsche e a prerrogativa da ciência como forma de inverdade...

verdadeiro e falso, atribuindo outro significado a esses adjetivos, sobre um fundo de inverdade e referindo-se a certa noção de realidade.

O que tradicionalmente se chama de "verdade", assegura Nietzsche em um fragmento póstumo já mencionado, consiste num "sistema de falsificação por princípio" útil à conservação de certa espécie animal: “e, já que uma espécie de animal nada conhece de mais importante do que conservar-se, então seria permitido falar de "verdade' nesse caso" (Nachlass/FP 1888, 14[153], KSA 13.336). Numa anotação póstuma anterior, já se podia ler:

\begin{abstract}
"Verdade": em meu modo de pensar, não designa necessariamente uma oposição ao erro, mas, nos casos mais fundamentais, apenas uma posição de diferentes erros em relação uns com os outros: um [erro] é mais antigo, mais profundo do que outros, talvez até mesmo inexterminável, na medida em que um ser orgânico de nossa espécie não poderia viver sem ele; no entanto, outros erros não nos tiranizam de igual modo como condições de vida, mas, pelo contrário, à diferença de tais "tiranos", podem ser eliminados e "refutados". Uma suposição que seja irrefutável, - por que deveria ser ela, só por isso, verdadeira? (Nachlass/FP 1885, 38[4], KSA 11.598) ${ }^{16}$.
\end{abstract}

Em textos semelhantes aos mencionados, a noção de verdade possui duplo sentido, um presumido e outro efetivo: de um lado, ela designa supostamente a correspondência entre aquilo a que ela se aplica e a realidade em si; de outro, ela significa efetivamente que aquilo a que ela se aplica é indispensável à vida. Já observamos que não tem sentido tomar a verdade como adequação ao mundo em si, pois a inverdade, a não correspondência, revela-se fundamental. Por conseguinte, não se pode opor o conceito de verdade, entendido como correspondência à realidade em si, ao conceito de erro, compreendido como não correspondência; é preciso, isto sim, subsumir o conceito de verdade ao de erro, já que existem apenas erros, não correspondência, "inverdade fundamental no conhecimento" (Nachlass/FP 1881,

16 Em outra anotação, Nietzsche assevera: "Verdade é a espécie de erro sem a qual uma determinada espécie de seres vivos não poderia viver" (Nachlass/FP 1885, 34[253], KSA 11.506). 
Corbanezi, E.

11 [326], KSA 9.568). Eis por que mesmo aquilo que, de um ponto de vista axiológico, considera-se como "verdadeiro" graças ao seu caráter indispensável à conservação de uma determinada forma de vida não constitui uma "verdade" entendida, de um ponto de vista cognitivo, como adequação ao mundo em si: aqui, o que se chamou de "verdade", com o propósito de indicar sua correspondência à realidade em si, é a rigor uma espécie de erro, de não correspondência. $\mathrm{O}$ fragmento póstumo mencionado acima ${ }^{17}$ também busca evidenciar um engano quanto ao significado efetivo do epíteto "verdadeiro" no uso que dele se faz tradicionalmente: com tal qualificativo, acredita-se designar a correspondência entre o que é qualificado e a realidade em si, mas, a bem dizer, não se faz senão valorizar o que é indispensável à conservação da vida.

No entanto, embora num primeiro nível, fundamental e incontornável, o erro entendido como não correspondência seja exclusivo, ainda permanece possível, num segundo nível, distinguir os erros como, por assim dizer, erros-verdades e erros-erros. É o que se fez tradicionalmente, como sugere o fragmento póstumo citado há pouco $^{18}$. Todavia, costuma-se chamar elipticamente os erros-verdades tão somente de verdades e os erros-erros, de erros. $\mathrm{O}$ primeiro termo de cada um desses pares conceituais (erros-verdades e erros-erros) refere-se à não correspondência fundamental e universal, ao passo que o segundo termo (erros-verdades e erros-erros) indica a oposição entre erros e verdades em outro nível e noutro sentido, que diz respeito a uma certa relação com a vida: nesse segundo plano, "verdade" quer dizer indispensável para conservar a existência, enquanto "erro" tem o sentido de dispensável para a preservação da vida. Se num primeiro nível as pretensas verdades (como designação de suposta correspondência com o mundo em si) são, a bem dizer, meras espécies de erro (pois este, entendido como não correspondência, é

17 Nachlass/FP 1885, 38[4], KSA 11.598.

18 Nachlass/FP 1885, 38[4], KSA 11.598.

76 | Cad. Nietzsche, Guarulhos/Porto Seguro, v.42, n.1, p. 61-88, janeiro/abril, 2021. 
Nietzsche e a prerrogativa da ciência como forma de inverdade...

fundamental e universal), num segundo nível certos erros constituem uma espécie de verdade (quando designam o que é indispensável para conservar a vida) e se opõem a outros erros (que designam o que é dispensável para preservar a vida). A tradição engana-se ao acreditar que distingue o que julga ser verdadeiro do que julga ser falso tomando por critério efetivo a correspondência com o mundo em si; engana-se igualmente ao pensar que tal distinção ocorre num primeiro nível, pois aí reina a "inverdade fundamental" (Nachlass/ FP 1881, 11[326], KSA 9.568). Tal distinção baseia-se na mera utilidade para a conservação de uma determinada forma de vida. Por certo, nada impede que se nomeie "verdadeiro" o que se estima indispensável para preservar a existência. Daí não se segue, porém, que o que se designa verdade corresponda ao mundo em si. Com efeito, “a vida não é argumento" (FW/GC 121, KSA 3.477-478, RRFT): o fato de que algo a preserve não basta para considerá-lo como verdadeiro no sentido de adequado à realidade em si.

O próprio Nietzsche, contudo, toma a vida como critério para distinguir o verdadeiro do falso ${ }^{19}$. Mas ao menos em dois pontos tal operação difere do procedimento adotado pela tradição criticada pelo filósofo. Em primeiro lugar, o autor de Para além de Bem e Mal dá a ver que a sua distinção entre verdadeiro e falso ocorre sobre um fundo de inverdade, isto é, de não correspondência com a realidade em si: em todo caso, se "o mundo que nos diz respeito" pode ser "uma ficção", argumenta ele, então nada "obriga, em geral, a admitir uma oposição essencial entre "verdadeiro' e 'falso"; pelo contrário, "basta admitir graus de aparência" (JGB/BM 34, KSA 5.53-54, RRTF, pontuação alterada) ou, de acordo com o fragmento póstumo já mencionado, "graus do falso" (Nachlass/FP 1881, 11[326], KSA 9.568). Em segundo lugar, Nietzsche estabelece como fator decisivo não a preservação ou a ruína da vida tout court, mas o favorecimento ou o prejuízo do tipo de vida que ele estima ascendente; para o

19 Sobre a vida como critério de avaliação das avaliações, cf. Marton, 2014b, pp. 321-342. 
Corbanezi, E.

filósofo, o que conta é, portanto, a elevação ou o declínio da vida, tal como ele define essas duas situações. No entender do autor de Zaratustra, já apontamos, a visão cristã de mundo merece censura na medida em que considera como verdadeiro o que implica o declínio da vida e como falso o que produz a elevação da existência. Ora, tal repreensão sugere que deve valer o modo inverso de considerar. E, dado que Nietzsche desaprova o modo cristão de considerar porque não toca a realidade, pode-se inferir que o filósofo observa a sua própria posição como ancorada no mundo efetivo.

O filósofo reivindica, portanto, uma espécie de verdade. Com efeito, ao apresentar no "Prólogo" de $O$ Anticristo as condições para que se compreenda seu pensamento, ele menciona "a coragem para o proibido" e "uma nova consciência para verdades que até agora permaneceram mudas" (AC/AC, "Prólogo", KSA 6.167). No "Prólogo" de Ecce homo, empregando terminologia semelhante para definir sua própria filosofia, assevera: "Nitimur in vetitum: neste signo vencerá um dia minha filosofia, pois até agora o que se proibiu sempre, por princípio, foi somente a verdade" (EH/EH, "Prólogo", 3, KSA 6.259, RRTF).

Mas o que Nietzsche quer dizer ao reivindicar uma espécie de verdade? Em primeiro lugar, a noção de verdade desempenha um papel negativo em sua obra. Ela qualifica uma posição que, com justeza, indique que algo não existe (quando se trata de determinar se algo existe ou não) ou uma posição que, com correção, estabeleça o que algo não é (quando se trata de caracterizar algo existente): "a maioria das verdades, de fato, são apenas verdades negativas[:] 'isto e isso não são aquilo' (embora geralmente expressas de modo positivo). Aí reside a fonte de todo progresso do conhecimento" (Nachlass/FP 1880, 6[441], KSA 9.312). Com efeito, argumenta Nietzsche no fragmento póstumo em tela, ainda que o homem construa inevitavelmente um mundo pleno de falsidade, é-lhe sempre possível "refinar" e "reduzir" os erros, mediante, por exemplo, a descoberta de contradições. As 
Nietzsche e a prerrogativa da ciência como forma de inverdade...

verdades negativas, isto é, as negações corretas, contribuem para afastar erros: "O caráter negativo da 'verdade' - como supressão de um erro, de uma ilusão" (Nachlass/FP 1884, 25[165], KSA 11.58). É precisamente essa tarefa negativa que, em Humano, Demasiado Humano, vemos atribuída ao pensamento científico: realizando uma "história genética do pensar", a ciência poderia mostrar, embora apenas parcialmente, que "aquilo que agora denominamos mundo é o resultado de uma multidão de erros e fantasias" (MA I/ HH I 16, KSA 2.37, RRTF ${ }^{20}$.

Em $O$ Anticristo, as noções de verdade e de ciência, entendida em sentido amplo como conhecimento em geral ${ }^{21}$ e em sentido estrito como âmbitos particulares de saber ${ }^{22}$, também parecem desempenhar esse papel negativo, na medida em que são empregadas para indicar a falsidade, a inverdade, do cristianismo. Nietzsche desacredita essa religião por ter ela desprezado as conquistas científicas do mundo antigo:

Todos os pressupostos para uma cultura douta, todos os métodos científicos já estavam presentes, já se havia fixado a grande, a incomparável arte de ler bem - esse pressuposto para a tradição da cultura, para a unidade da ciência; a ciência natural, em aliança com a matemática e a mecânica, estava muito bem encaminhada - o sentido dos fatos, o último e mais valioso de todos os sentidos, tinha suas escolas, sua tradição já de séculos! (AC/ AC 59, KSA 6.247-248, PCS).

Apesar de tamanho desprezo por parte do cristianismo, "hoje em dia reconquistamos [...] toda a retidão do conhecimento" (AC/ AC 59, KSA 6.247-248, PCS). Levando em conta a reconquista

20 Mais adiante no mesmo livro, Nietzsche afirma que "a ciência da arte" também deve executar essa função negativa, denunciando a ilusão segundo a qual o que é perfeito não vem a ser. Cabe a essa ciência "apontar as falsas conclusões e maus costumes do intelecto, que o fazem cair nas malhas do artista” (MA I/ HH I 145, KSA 2.141, PCS)

21 Cf. AC/AC 48, KSA 6.226-227.

22 Cf. AC/AC 47, KSA 6.225-226.

Cad. Nietzsche, Guarulhos/Porto Seguro, v.42, n.1, p. 61-88, janeiro/abril, 2021.| 79 
Corbanezi, E.

da probidade intelectual, Nietzsche julga poder afirmar que, "na época moderna, na nossa época", o reconhecimento da falsidade do cristianismo constitui um saber incontornável, que mesmo o sacerdote não tem o direito de ignorar:

Nossa época sabe [...], já não aguentamos, se um sacerdote apenas pronuncia a palavra "verdade". Hoje temos de saber, mesmo com uma exigência ínfima de retidão, que um teólogo, um sacerdote, um papa, não apenas erra, mas mente a cada frase que enuncia - que já não é livre para mentir por "inocência", por "insciência". Também o sacerdote sabe, como sabe todo indivíduo, que não existe mais "Deus", "pecador", "Salvador" - que "livre-arbítrio", "ordem moral do mundo", são mentiras: a seriedade, a profunda autossuperação do espírito já não permite a ninguém não saber a respeito disso... (AC/AC 38, KSA 6.210, PCS).

Os textos de Nietzsche indicam, portanto, que a verdade sobre o cristianismo é a sua inverdade, entendida em três sentidos conectados. Essa religião constitui uma inverdade primeiro porque a sua visão de mundo resulta de procedimentos julgados pela ciência como ilegítimos para o estabelecimento do que se pode qualificar de verdadeiro: tomam-se, por exemplo, bons sentimentos por argumentos e a convicção por critério da verdade; a adoção de meios inadequados para se estabelecer o que se crê poder chamar de verdade expõe a ausência de probidade e de consciência intelectual no cristianismo ${ }^{23}$. Além disso, a inverdade do cristianismo deve-se ao fato de que sua visão de mundo, apoiada em meios duvidosos do ponto de vista cognitivo, não pode ser considerada como verdadeira, já que não representa algo real e existente, mas apenas como imaginária e fictícia - ainda que a representação desse mundo fictício produza efeitos (nocivos, segundo Nietzsche) e que, nesse sentido, esse universo imaginário possa ser qualificado de efetivo (wirklich). Enfim, o cristianismo constitui uma inverdade porque aqueles que sustentam essa visão

23 Cf. AC/AC 52, KSA 6.232-234.

80 | Cad. Nietzsche, Guarulhos/Porto Seguro, v.42, n.1, p. 61-88, janeiro/abril, 2021. 
Nietzsche e a prerrogativa da ciência como forma de inverdade...

de mundo, notadamente o teólogo, o sacerdote e o papa, mentem: com efeito, dado o nível alcançado pelo conhecimento científico, eles não têm o direito de acreditar na verdade dessa concepção de mundo, como se o universo nela representado existisse para além da representação; assim, mentirosos e inverazes, eles são ímprobos em relação a si próprios e em relação àqueles a quem apresentam como verdadeira a visão de mundo cristã.

Identificar erros e ilusões, já apontamos, constitui um papel negativo das noções de conhecimento e de verdade: conhecer o caráter errôneo e ilusório de algo equivale a saber que esse algo não existe ou a saber o que esse algo não é. Em resumo, reconhecer o caráter errôneo e ilusório de algo consiste em evidenciar a inverdade e a irrealidade desse algo, o mesmo é dizer, a verdade de sua inverdade e a realidade de sua irrealidade. Ora, esse aspecto negativo do conhecimento e da noção de verdade vale como "uma única realidade" (AC/AC 39, KSA 6.212, PCS ${ }^{24}$ capaz de desmontar o cristianismo, na medida em que se expõem, sob vários aspectos, a inverdade e a irrealidade do mundo que essa religião representa - o mesmo é dizer, a verdade de sua inverdade e a realidade de sua irrealidade.

Todavia, embora a identificação de formas de inverdade possa ser considerada, em sentido negativo, como uma espécie de conhecimento e de verdade, discernir e suprimir inverdades não implica, por si só, estabelecer positivamente outros conhecimentos e verdades: dizer o que algo não é produz apenas uma indeterminação, pois não equivale automaticamente a determinar de modo positivo o que esse algo é - ainda que uma negação possa contribuir para a determinação positiva de algo, já que exclui o que não pode constituir esse algo cujas propriedades devem ser indicadas. Com efeito, se, no fragmento póstumo mencionado há pouco ${ }^{25}$, Nietzsche considera a supressão de erros e ilusões como uma face negativa da verdade, em

24 Cf. ainda AC/AC 47, KSA 6.225-226.

25 Nachlass/FP 1884, 25[165], KSA 11.58.

Cad. Nietzsche, Guarulhos/Porto Seguro, v.42, n.1, p. 61-88, janeiro/abril, 2021.| 81 
Corbanezi, E.

outra anotação, é ao observar sua face positiva que ele afirma que "a destruição de uma ilusão ainda não dá nenhuma verdade, mas apenas um fragmento a mais de ignorância" (Nachlass/FP 1885, 35[47], KSA 11.533). Quando considerada como destruição de ilusões, "a evolução da ciência dissolve cada vez mais o 'conhecido’ em um desconhecido" e "prepara uma soberana ignorância" (Nachlass/FP 1886-1887, 5[14], KSA 12.189).

Nietzsche, portanto, não parece limitar-se a reivindicar verdades em sentido negativo: de fato, ele não se contenta em identificar e afastar inverdades. Quando, por exemplo, mais do que assegurar que a maneira cristã de subsumir aos conceitos de verdadeiro e de falso é errada, o autor de $O$ Anticristo assevera que ela se encontra invertida, ele sugere que o modo inverso de subsumir seria o correto: este constituiria o verdadeiro modo de subsumir aos conceitos de verdadeiro e de falso. Todavia, uma vez que num primeiro nível, se a noção de verdade é considerada a partir da ideia de correspondência à realidade em si, faz-se necessário admitir a "inverdade fundamental no conhecimento" (Nachlass/FP 1881, 11[326], KSA 9.568), isto é, a sua inadequação ao mundo em si, então é preciso tentar compreender como se justifica, de um ponto de vista cognitivo, a oposição nietzschiana a certos erros em favor de outros, o mesmo é dizer, a rejeição a certas formas de não correspondência em favor de outras. Dito de outro modo, é preciso entender como o autor restabelece, num segundo nível e com outro sentido, a oposição, impossível no primeiro nível e com base na ideia de correspondência ao mundo em si, entre verdades e erros ou, para falar de modo não elíptico, a oposição entre erros-verdades e erros-erros, fazendo intervir, em apoio à sua posição, uma concepção de realidade dada pela ciência. Para tanto, temos de saber como determinar positivamente o que Nietzsche julga digno de ser chamado de verdade e em que sentido o mundo fictício da ciência pode ser 
Nietzsche e a prerrogativa da ciência como forma de inverdade...

considerado como verdadeiro e real, enquanto o mundo fictício da religião não é apreciado do mesmo modo ${ }^{26}$.

De acordo com Nietzsche, a ciência, o conhecimento e a verdade têm um caráter necessariamente condicionado e relativo, quer dizer, não incondicionado e não absoluto. Tal concepção desempenha um papel manifestamente crítico em seu pensamento. Mas ela exerce também uma função positiva, na medida em que lhe permite considerar, ao menos até que se demonstre o contrário, algo como "ciência", como "conhecimento" e como "verdade".

Num fragmento póstumo em que se coloca "contra o preconceito científico", Nietzsche busca inviabilizar toda pretensão de apreender "as coisas em si" ou "algo incondicionado" (Nachlass/FP 18851886, 2[154], KSA 12.141). Ao assegurar que "conhecer é sempre "colocar-se-em-relação-condicional-com-algo" (Nachlass/FP 18851886, 2[154], KSA 12.142), ele indica que não há conhecimento absoluto nem conhecimento do absoluto. Numa nota póstuma datada de anos anteriores, o autor precisa que "todas as nossas relações, por mais exatas que possam ser elas, são descrições do homem, não do mundo: são as leis dessa ótica suprema, para além da qual não nos é possível ir" (Nachlass/FP 1880, 6[429], KSA 9.308). Em outro fragmento póstumo, ele assevera ainda: "Para nós, o mundo é, portanto, a soma das relações relativamente a uma esfera limitada de errôneas admissões fundamentais. As leis da ótica são todas erros, também as da acústica" (Nachlass/FP 1880, 6 [441], KSA 9.312).

A ciência, como todos os outros domínios, não pode livrar-se de seu caráter condicionado e relativo ou, mais especificamente, da ótica humana, com todos as limitações e os erros nela implicados. Daí não se segue a impossibilidade da ciência, mas apenas a necessidade de identificar e de aprimorar as condições que a determinam. Em Crepúsculo dos Ídolos, Nietzsche assevera: "Nós possuímos ciência, hoje, exatamente na medida em que resolvemos aceitar o testemunho

26 Cf. AC/AC 15, KSA 6.181-182.

Cad. Nietzsche, Guarulhos/Porto Seguro, v.42, n.1, p. 61-88, janeiro/abril, 2021. | 83 
Corbanezi, E.

dos sentidos - em que aprendemos a ainda aguçá-los, armá-los, pensá-los até o fim" (GD/CI, A “razão" na filosofia 3, KSA 6.76, PCS).

Ainda que não possamos nos livrar das condições humanas que determinam nossas interpretações de mundo, é possível, tomando consciência de tal limitação, distinguir e hierarquizar as diferentes formas de antropomorfismo. Para tanto, pode-se comparar a ciência com outros domínios, como a religião, conforme faz Nietzsche em $O$ Anticristo, ou ainda cotejar os diversos estágios do pensamento científico, tal como procede o autor em A Gaia Ciência, num parágrafo intitulado "Causa e efeito":

"Explicação", dizemos; mas é a "descrição" o que nos distingue de estágios anteriores do conhecimento e da ciência. Nós descrevemos melhor - e explicamos tão pouco como aqueles que nos precederam. Descobrimos múltiplas sucessões, ali onde o homem e pesquisador ingênuo de culturas anteriores via apenas duas coisas, "causa" e "efeito", como se diz; aperfeiçoamos a imagem do devir, mas não fomos além dessa imagem, não vimos o que há por trás dela. [...] Basta considerar a ciência a humanização mais fiel possível das coisas, aprendemos a nos descrever de modo cada vez mais preciso, ao descrever as coisas e sua sucessão. (FW/GC 112, KSA 3.472-473, PCS) ${ }^{27}$.

A ciência, portanto, não pode senão formar uma imagem antropomórfica do mundo. Evoluindo, todavia, o pensamento científico percorre diversos estágios e se revela perfectível. Ele se aperfeiçoa na medida em que torna mais precisas as suas observações e descrições, processo cujo limite é a maior "exatidão possível" para o homem (Nachlass/FP 1881, 11[255], KSA 9.538, EC). Tal aperfeiçoamento não se mede pela referência ao mundo em si, o que seria impossível. A ciência acura-se pelo refinamento da ótica humana, a única de que o homem dispõe e da qual não pode esquivar-se. O grau de perfeição científica mede-se, por conseguinte, com base no aprimoramento

27 Ver ainda o parágrafo 246 da mesma obra.

84 | Cad. Nietzsche, Guarulhos/Porto Seguro, v.42, n.1, p. 61-88, janeiro/abril, 2021. 
Nietzsche e a prerrogativa da ciência como forma de inverdade...

dos fatores que determinam a imagem antropomórfica do mundo e, mais precisamente, a imagem antropomórfico-científica do mundo. Não se estabelece sem disputa quais são esses fatores nem o que significa aperfeiçoamento. Parece-nos que, no entender Nietzsche, para aperfeiçoar a ciência mediante o aprimoramento dos fatores que determinam a imagem antropomórfico-científica do mundo, faz-se necessário aguçar os sentidos ${ }^{28}$, evitar os "maus hábitos do raciocínio" (MA I/ HH I 30, KSA 2.50 PCS) e utilizar com rigor cada vez maior os conceitos sem os quais o homem talvez não possa viver, como o de causalidade ${ }^{29}$. É a imagem antropomórfico-científica do mundo, concebida a partir da ótica humana aperfeiçoada e em constante aperfeiçoamento, que tem valor e autoridade cognitiva e que se pode qualificar em sentido positivo, ao menos provisoriamente, de científica e de verdadeira.

Se inevitavelmente antropomorfizamos o mundo, a ciência é, para Nietzsche, a humanização mais fiel possível: ela constitui o melhor aperfeiçoamento alcançável das condições necessariamente humanas de conhecimento. Assim, embora não consiga apreender a realidade em si, o pensamento científico pode, dentro das possibilidades e limitações típicas das condições humanas de conhecimento, formar

28 Cf. GD/CI, A “razão” na filosofia 3, KSA 6.75-76.

29 Ainda que os conceitos de causa e efeito não permitam apreender o mundo em si, eles podem e devem ser utilizados como "ficções convencionais" (JGB/BM 21, KSA 5.36, PCS). Contudo, não se costuma empregar tais noções do mesmo modo. Notam-se diferenças no uso do conceito de causalidade quando se comparam os diversos estágios do pensamento científico (FW/GC 112, KSA 3.472-473) ou ainda quando se contrastam a ciência e a religião. Em $O$ Anticristo, Nietzsche atribui à ciência "a sadia noção de causa e efeito" (AC/AC 49, KSA 6.228, PCS). Já na interpretação sacerdotal do mundo, que toma a bondade por recompensa e a felicidade por castigo divino, "o conceito natural de 'causa' e "efeito' é definitivamente virado de cabeça para baixo" (AC/AC 25, KSA 6.194, PCS). Excluindo "a causalidade natural", a única admitida pela ciência, a visão religiosa de mundo promove, ao contrário, "uma causalidade antinatural", da qual decorre "toda a restante inaturalidade" (AC/ AC 25, KSA 6.194, PCS). Com efeito, o "puro mundo de ficções" do cristianismo compõe-se apenas de causas e efeitos imaginários (AC/AC 15, KSA 6.181, RRTF). Assim, Nietzsche indica que é possível e necessário aperfeiçoar a concepção e o uso dos conceitos de causa e efeito, mesmo que eles não eliminem o caráter condicionado e relativo do conhecimento. Sobre esse tema, cf. ainda: Nachlass/FP 1884, 26[12], KSA 11.152-153; M/A 10, KSA 3.24-25; JGB/BM 36, KSA 5.54-55; GD/CI, Os quatro grandes erros 3, KSA 6.90-91.

Cad. Nietzsche, Guarulhos/Porto Seguro, v.42, n.1, p. 61-88, janeiro/abril, 2021. | 85 
a imagem antropomórfica do mundo mais rigorosa possível do ponto de vista cognitivo. De um lado, essa imagem resulta da identificação e do afastamento de certas inverdades (o que caracteriza a verdade em sentido negativo, a qual produz apenas indeterminações); de outro lado, esse descarte de erros beneficia certas concepções que, num primeiro nível, também são errôneas, pois não correspondem ao mundo em si, mas que, num segundo nível, podem ser consideradas, mesmo que provisoriamente, como verdades em sentido positivo, na medida em que oferecem determinações positivas do mundo tal como concebido pela ciência. Portanto, é a ciência - enquanto imagem de mundo que resulta do melhor aperfeiçoamento possível das condições necessariamente humanas de conhecimento - que tem autoridade para distinguir e hierarquizar os diferentes graus de falsidade constitutivos de toda imagem humana de mundo. Daí Nietzsche, em $O$ Anticristo, recorrer à ciência para rejeitar o cristianismo. 
Nietzsche e a prerrogativa da ciência como forma de inverdade...

\title{
Nietzsche and the prerogative of science as a form of untruth: scientific worldview versus Christian worldview
}

\begin{abstract}
Starting from the analysis of The Antichrist, we investigate the function that Nietzsche attributes to science, understood as a form of untruth, in relation to other forms of untruth, such as Christianity. First, we seek to show that, in this writing, the author establishes the incompatibility between science and Christianity by assigning them specific and irreconcilable characteristics (such as the intellectual probity, proper to science, and the requirement of faith, typical of Christianity). Then, we show that qualifications such as "false", "erroneous", "fictitious" and "lying", applied in a derogatory way to the religious conception of the world in The Antichrist, also determine, in other writings, scientific knowledge. Now, if the Christian and scientific worldviews have similar characteristics, why does Nietzsche turn to science to reject Christianity?
\end{abstract}

Keywords: Science, Christianity, truth, untruth, errors-truths, errors-errors.

\section{Referências}

MARTON, S. Nietzsche: das forças cósmicas aos valores humanos. $2^{\mathrm{a}}$ edição. Belo Horizonte: Editora UFMG, 2000.

. O Anticristo. Cristianismo: da má filologia à corrupção dos instintos. In: - Nietzsche e a arte de decifrar enigmas. Treze conferências europeias.

São Paulo: Edições Loyola, 2014a, pp. 227-244. 
Corbanezi, E.

. À la recherche d'un critère d'évaluation des évaluations. Les notions de vie et de valeur chez Nietzsche. In: DENAT, C.; WOTLING, P. (Orgs.). Les hétérodoxies de Nietzsche. Lectures du Crépuscule des idoles. Reims: Éditions et presses universitaires de Reims, 2014b, pp. 321-342.

NIETZSCHE, F. Friedrich Nietzsche: Sämtliche Werke. Kritische Studienausgabe [KSA]. Munique: Walter de Gruyter/Deutscher Taschenbuch Verlag, 1999.

. Friedrich Nietzsche: Obras Incompletas. Trad. Rubens Rodrigues Torres Filho. São Paulo: Editora Nova Cultural, 2000.

. Humano, Demasiado Humano: um Livro para Espíritos Livres. Trad. Paulo César de Souza. São Paulo: Companhia das Letras, 2000.

. Aurora: Reflexões sobre os Preconceitos Morais. Trad. Paulo César de Souza. São Paulo: Companhia das Letras, 2004.

. A Gaia Ciência. Trad. Paulo César de Souza. São Paulo: Companhia das Letras, 2001.

. Além do Bem e do Mal: Prelúdio a uma Filosofia do Futuro. Trad. Paulo César de Souza. São Paulo: Companhia das Letras, 2005.

. Crepúsculo dos Ídolos, ou, Como se Filosofa com o Martelo. Trad. Paulo César de Souza. São Paulo: Companhia das Letras, 2006.

. O Anticristo: Maldição ao Cristianismo: Ditirambos de Dionísio. Trad. Paulo César de Souza. São Paulo: Companhia das Letras, 2007.

SALANSKIS, E. Sobre o eugenismo e sua justificação maquiaveliana em Nietzsche. Trad. Eder Corbanezi. In: Cadernos Nietzsche, n. 32, pp. 167-201, 2013.

SOMMER, A. U. Friedrich Nietzsches "Der Antichrist". Ein philosophisch-historischer Kommentar. Basileia: Schwabe \& Co. Verlag, 2000.

WOTLING, P. “Oui, l'homme fut un essai”. La philosophie de l'avenir selon Nietzsche. Paris: PUF, 2016.

Enviado: 16/10/2020

Aceito: 18/11/2020

88 | Cad. Nietzsche, Guarulhos/Porto Seguro, v.42, n.1, p. 61-88, janeiro/abril, 2021. 